\title{
Studies of Copolyesters. Thermal Characterization and Kinetics of Thermal Degradation of Poly(ethylene/trimethylene terephthalate) Copolyesters ${ }^{\dagger}$
}

\author{
E. PONNUSAMY* and T. BALAKRISHNAN \\ Department of Physical Chemistry, University of Madras, \\ Guindy Campus, Madras 600025, India
}

(Received May 22, 1984)

\begin{abstract}
Random copolyesters of dimethyl terephthalate (DMT), ethylene glycol (EG) and propane-1,3-diol (PrG) and the homo-polyesters poly(ethylene terephthalate) (PET) and poly(trimethylene terephthalate) (PPrT) have been subjected to differential thermal analysis (DTA) and thermogravimetry (TG). Thermodynamic parameters like enthalpy of fusion $\left(\Delta H_{\mathrm{f}}\right)$, entropy of fusion $\left(\Delta S_{\mathrm{f}}\right)$ and percent crystallinity $\left(X_{\mathrm{c}}\right)$ are discussed in terms of structural differences, particularly the effect of composition and chain flexibility. Kinetic order and activation energy for the thermal degradation of the copolyesters are discussed.
\end{abstract}

KEY WORDS DTA / Enthalpy of Fusion / Entropy of Fusion / Percent Crystallinity / TG / Kinetic Order / Activation Energy /

The synthesis and characterization of terephthalate copolyesters with varying percentage of ethylene glycol and propane-1,3-diol and the homo-polyesters poly(ethylene terephthalate) and poly(trimethylene terephthalate) were reported in a previous article. ${ }^{1}$ Thermoanalytical methods, such as differential thermal analysis (DTA), thermogravimetric analysis (TG), and thermovolumetry have been employed increasingly in the investigation of chemical reactions in the liquid and solid states at elevated temperatures. DTA studies provide structural information on comonomer distribution and crystallinity of the copolymers. ${ }^{2}$ Very little has been reported concerning the degradation studies of polyesters. ${ }^{3-8}$ In the present study, we report the thermal and degradation kinetic phenomena of terephthalate copolyesters of ethylene glycol and propane1,3-diol.

\section{EXPERIMENTAL METHODS}

The synthesis and characterization of the copolyesters used in this study have been given elsewhere. ${ }^{1}$

A Mettler system TA 2000 DTA was used to record the DTA curves. Typically, 5-10 mg of the sample was encapsulated in aluminium sample pans and empty pans were used as references. The lids of the pans were perforated with a needle so that the measurements were carried out in air atmosphere. Dynamic studies were performed by heating the material at a rate of $10 \mathrm{~K} \mathrm{~min} \min ^{-1}$ in a DTA cell. The heat of fusion, $\Delta H_{\mathrm{f}}$, of the copolyesters were determined by comparing the area under the endothermic peak to the area of standard indium endotherm. ${ }^{1,9-11}$ The per cent crystallinity, $X_{\mathrm{c}}$, of the copolyesters were calculated by the following equation ${ }^{10-12}$ :

\footnotetext{
${ }^{\dagger}$ Accepted for presentation in the 1st SPSJ International Polymer Conference, Kyoto, Japan, August 20-24, 1984.

* Present Address: Department of Physiology and Biophysics, University of Illinois at Chicago, Box 6998, Chicago, Illinois 60680, U.S.A.

* To whom communications to be sent.
} 


$$
\% X_{\mathrm{c}}=\frac{\Delta H_{\mathrm{f}}(\mathrm{EG} \times \mathrm{M} 1)+(\mathrm{PrG} \times \mathrm{M} 2)}{\Delta H_{\mathrm{f}}^{0}(\mathrm{EG} \times \mathrm{M} 1)} \times 100
$$

where $\mathrm{EG}=\mathrm{mol} \%$ of ethylene terephthalate in the copolymer; $\mathrm{M1}=$ molecular weight of ethylene terephthalate repeat unit (192); $\mathrm{PrG}=\mathrm{mol} \%$ of trimethylene terephthalate; M2 = molecular weight of trimethylene terephthalate repeat unit (206) and $\Delta H_{\mathrm{f}}^{0}=$ the heat of fusion per gram of repeat unit of poly(ethylene terephthalate) (PET) $\left(32.2 \mathrm{cal} \mathrm{g}^{-1}\right)$.

Thermal degradation of the copolyesters was studied by means of dynamic thermogravimetry with a Stanton Redcroft TG-750 model thermobalance; $5 \mathrm{mg}$ of the sample were heated in nitrogen atmosphere at a heating rate of $10 \mathrm{~K} \mathrm{~min}^{-1}$. A platinum-rhodium thermocouple was used to measure the temperatures.

\section{KINETIC TREATMENT}

The order and activation energy for the major decomposition reaction steps were calculated by various methods. Most kinetic treatments are based on the following relationships:

$$
\frac{\mathrm{d} c}{\mathrm{~d} t}=k f(c)
$$

where $c$ is the conversion, $t=$ time, $k=\mathrm{a}$ temperature dependent rate constant and $f(c)=\mathrm{a}$ temperature independent function of $c$. The constant $k$ is generally assumed to follow a law of the form:

$$
k=A \mathrm{e}^{-E /(R T)}
$$

where $A=$ pre-exponential factor, $E=$ activation energy, $R=$ gas constant and $T=$ absolute temperature. In homogeneous kinetics, conversion is defined in terms of concentration, and the conversion function is assumed to have the form:

$$
f(c)=(1-c)^{n}
$$

where $n=$ order of reaction. By combining eq
$2-4$ and including the rate of temperature rise, $\mathrm{d} T / \mathrm{d} t$, the following integral form of the equation can be written:

$$
\int_{0}^{c} \mathrm{~d} c /(1-c)^{n}=\frac{A}{B} \int_{0}^{c} \mathrm{e}^{-E /(R T)} \mathrm{d} T
$$

where $A$ and $B$ are constants. Integration of the terms on the left hand side gives:

$$
\begin{aligned}
\int_{0}^{c} \mathrm{~d} c /(1-c)^{n} & =-\left[(1-c)^{1-n}-1\right] /(1-n) \\
& =-\ln (1-c) \quad \text { for } n \neq 1 \\
& \text { for } n=1
\end{aligned}
$$

For the right hand side of eq 5, various authors used different approximations for the calculation of the kinetic parameters: Coats and Redfern ${ }^{13}$ :

$$
\int_{0}^{T} \mathrm{e}^{-E /(R T)} \mathrm{d} T=\left(R T^{2} / E\right)(1-2 R T / E) \mathrm{e}^{-E /(R T)}
$$

Plot: $\log \left[\{\ln (1-c)\} / T^{2}\right]$ vs. $1 / T$

$$
\text { for } n=1
$$

Doyle ${ }^{14}$ :

$$
\begin{gathered}
\int_{0}^{T} \mathrm{e}^{-E /(R T)} \mathrm{d} T=-2.315-0.4567 E /(R T) \\
\text { for } E /(R T) \geqslant 20
\end{gathered}
$$

Plot: $\ln (1-c) \quad$ vs. $1 / T$ for $n=1$

Murray and White ${ }^{15}$ :

$\int_{0}^{T} \mathrm{e}^{-E /(R T)} \mathrm{d} T=\left(R T^{2} / E\right) \mathrm{e}^{-E /(R T)}$

Plot: $[\ln \{\ln (1-c)\}-2 \ln T] v s .1 / T$

$$
\text { for } n=1
$$

The activation energies are determined graphically from the above equations, assuming the correct order of the reaction $(n=1$ for the present system) which is established by differential methods wherever necessary. 


\section{RESULTS AND DISCUSSION}

The compositions and molecular weights of the copolyesters are given in Table I. When the copolyesters were heated at a rate of $10 \mathrm{~K} \mathrm{~min}$ min $^{-1}$ in DTA cell, it was found that a sharp endotherm occurred around 180$240^{\circ} \mathrm{C}$ depending upon the comonomer contents (EG and PrG) in the copolyester (PET, $246^{\circ} \mathrm{C}$; A4, $238.2^{\circ} \mathrm{C}$; A3, $237.0^{\circ} \mathrm{C}$; $\mathrm{A}, 186.7^{\circ} \mathrm{C}$, and PPrT, $225.2^{\circ} \mathrm{C}$, Table I). This endotherm was attributed to the melting of the copolyester and the corresponding temperature is the melting temperature of the copolyester. As the PrG content increases the copolyester becomes more amorphous and hence there is no melting temperature for the copolyesters $\mathrm{A} 1$ and $\mathrm{A} 2$. When the composition of $\mathrm{PrG}$ reaches 100 $\mathrm{mol} \%$, that is homopolymer, the polymer becomes crystalline again. The melting temperature-composition relations for this component follow an independent curve, so that an eutectic type minimum results at the inter-

Table I. Compositions and molecular weight of the copolyesters

\begin{tabular}{|c|c|c|c|}
\hline \multirow{2}{*}{ Polymer } & \multicolumn{2}{|c|}{ NMR Composition $/ \mathrm{mol}^{\circ} \%$} & \multirow{2}{*}{$\begin{array}{c}\text { Molecular } \\
\text { weight } \\
\left(M_{n}\right)\end{array}$} \\
\hline & EG & PrG & \\
\hline PPrT & 0 & 100.0 & 5941 \\
\hline A2 & 22.3 & 77.7 & 1490 \\
\hline Al & 29.0 & 71.0 & 1612 \\
\hline A & 43.8 & 56.2 & 3052 \\
\hline $\mathrm{A} 3$ & 74.7 & 25.3 & 1750 \\
\hline A4 & 83.5 & 16.5 & 2010 \\
\hline PET & 100.0 & 0 & 3303 \\
\hline
\end{tabular}

Table II. Effect of composition on the thermodynamic properties and crystallinity of copolyesters

\begin{tabular}{|c|c|c|c|c|}
\hline \multirow{2}{*}{ Polymer } & \multirow{2}{*}{$\begin{array}{l}\mathrm{Mol}^{\circ} \% \\
\text { of } \operatorname{PrG}\end{array}$} & \multirow{2}{*}{$\frac{\Delta H_{\mathrm{f}}}{\operatorname{calg}^{-1}}$} & \multirow{2}{*}{$\frac{\Delta S_{\mathrm{f}}}{\mathrm{cal} \mathrm{deg}^{-1} \mathrm{~mol}^{-1}}$} & \multirow{2}{*}{$\% X_{\mathrm{c}}$} \\
\hline & & & & \\
\hline A4 & 16.5 & 18.82 & 7.07 & 58.5 \\
\hline A3 & 25.3 & 15.35 & 5.78 & 47.8 \\
\hline A & 56.2 & 12.07 & 5.04 & 38.0 \\
\hline
\end{tabular}

section of the two curves. ${ }^{11,16-18}$ This is a typical behavior of random copolymers when studied over a wide range of compositions.

The $\Delta H_{\mathrm{f}}$ and per cent crystallinity-composition relationship of the copolyesters are shown in Table II. As the PrG content increases in the copolyester, the $\Delta H_{\mathrm{f}}$ and per cent crystallinity decreases upto $56 \mathrm{~mol}^{\circ} \%$ of PrG and then the polymer becomes amorphous. The decrease in melting temperature $\left(T_{\mathrm{m}}\right)$ with increasing PrG content in the copolymer is in agreement with the theory of equilibrium melting of random copolymers. ${ }^{19}$ This theory predicts a depression in $T_{\mathrm{m}}$ caused by the non-crystallizing units according to the equation:

$$
1 / T_{\mathrm{m}}-1 / T_{\mathrm{m}}^{0}=-\frac{R}{\Delta H_{\mathrm{f}}^{0}} \ln X_{\mathrm{A}}
$$

where $T_{\mathrm{m}}=$ the melting temperature of the copolymer; $T_{\mathrm{m}}^{0}=$ the melting temperature of the homopolymer; $\Delta H_{\mathrm{f}}^{0}=$ the heat of fusion per repeat unit of the homopolymer, and $X_{\mathrm{A}}=$ the mole fraction of the crystallizable units. The melting point depression is dependent on the heat of fusion per mole of the crystallizing unit and on the sequence propagation probability $p$, which is suggested in random copolymers can be identified with $X_{\mathrm{A}}{ }^{19}$ Using Flory equation, the $T_{\mathrm{m}}^{0}$ calculated from the $1 / T_{\mathrm{m}} v s$. $-\ln X_{\mathrm{A}}$ plot was in good agreement with the DTA $T_{\mathrm{m}}$ of PET ( $T_{\mathrm{m}}$ for PET by the Flory equation is $242.5^{\circ} \mathrm{C}$; and by DTA is $246.0^{\circ} \mathrm{C}$ ). The $\Delta H_{\mathrm{f}}^{0}$ (for PET) calculated by Flory equation is $2650 \mathrm{cal}$ per mol and by DTA analysis is $11920 \mathrm{cal}$ per mol. The values of $\Delta H_{\mathrm{f}}^{0}$ determined from an analysis of copolymer melting always differ by varying amounts from the values obtained by other methods. ${ }^{20}$

Figure 1 gives the thermogravimetry curves for the copolyester A and A1. The kinetics of thermal degradation of the copolyester was studied from the weight loss versus temperature curve using different approximation methods for the calculation of the kinetic 


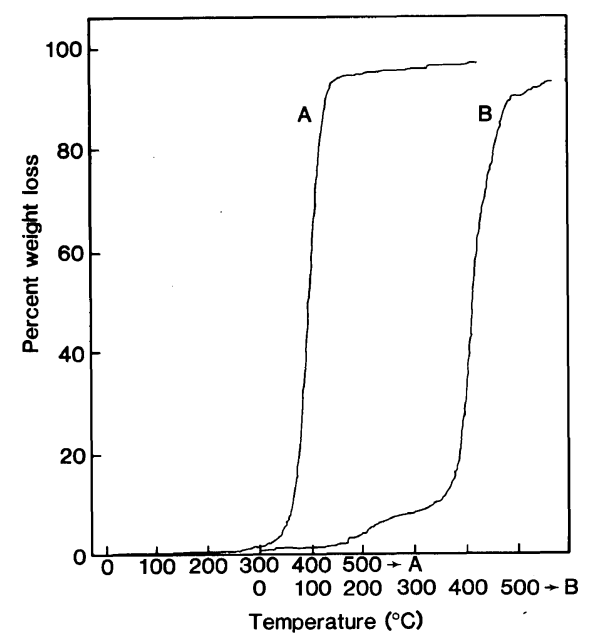

Figure 1. Thermogravimetry curves for terephthalate copolyester samples A (curve A) and Al (curve B), cf. Table I.

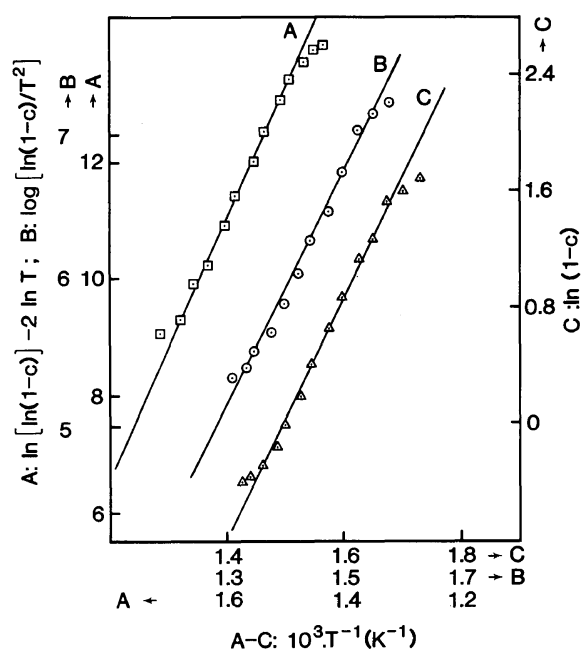

Figure 2. Calculation of activation energies $E$ for the degradation of terephthalate copolyester sample A ( $c f$. Table I) according to Murray and White ${ }^{15}$ (plot A), Coats and Redfern ${ }^{13}$ (plot B), and Doyle ${ }^{14}$ (plot C).

parameters (Coats and Redfern, ${ }^{13}$ Doyle ${ }^{14}$ and Murray and White ${ }^{15}$ ). Figure 2 shows the calculations of the activation energy for the copolyester A using the above methods for a first order reaction. The mechanism for the major degradation route was found to be unimolecular. The energies of activation for
Table III. Activation energies $E$ for the degradation of terephthalate homo- and co-polyesters of ethylene glycol and propane-1,3-diol according to different methods of evaluation

\begin{tabular}{|c|c|c|c|c|}
\hline \multirow{3}{*}{ Polymer $^{\mathrm{a}}$} & \multirow{3}{*}{$\frac{\begin{array}{c}\text { Temp of } \\
\text { degradation }\end{array}}{{ }^{\circ} \mathrm{C}}$} & \multicolumn{3}{|c|}{$E / \mathrm{kcal} \mathrm{mol}^{-1 \mathrm{~b}}$} \\
\hline & & \multirow{2}{*}{$\begin{array}{l}\text { Coats and } \\
\text { Redfern }\end{array}$} & \multirow{2}{*}{ Doyle $^{14}$} & \multirow{2}{*}{$\begin{array}{c}\text { Murray and } \\
\text { White }^{15}\end{array}$} \\
\hline & & & & \\
\hline PET & $311-448$ & 33 & 36 & 39 \\
\hline A & $301-457$ & 37 & 37 & 41 \\
\hline Al & $120-476$ & 18 & 17 & 17 \\
\hline PPrT & $285-448$ & 38 & 38 & 42 \\
\hline
\end{tabular}

a PET, poly(ethylene terephthalate); PPrT, poly(trimethylene terephthalate).

b In SI units $1 \mathrm{cal}=4.184 \mathrm{~J}$.

the homo- and copolyesters were calculated and listed in Table III. Major decompositions start around $325^{\circ} \mathrm{C}$ and are completed around $450^{\circ} \mathrm{C}$. From the activation energies, it is clear that as the PrG content increases in the copolymer chain, the copolymer needs less energy to degrade; that is the presence of long soft alkyl chain $\left(\mathrm{CH}_{2}-\mathrm{CH}_{2}-\mathrm{CH}_{2}\right)$ makes the polymer more susceptible to degradation because of the decrease in crystallinity. The variation of the activation energies calculated by different methods is due to various approximations employed in the calculation and lies within the experimental errors.

Acknowledgement. The authors wish to thank Dr. C. T. Vijayakumar for the DTA. One of the authors (E.P.) acknowledges the University Grants Commission, New Delhi for financial support.

\section{REFERENCES}

1. E. Ponnusamy and T. Balakrishnan, J. Macromol. Sci.-Chem., A22, No. 3 (1985).

2. G. A. Clegg, D. R. Gee, and T. P. Melia, Makromol. Chem., 120, 210 (1968).

3. R. T. Conley, Monographs in Macromolecular Chemistry, "Thermal Stability of Polymers," Vol. 1, Marcel Dekker Inc., New York, 1970, p 401.

4. Collected papers of W. H. Carothers on Polymerization, High Polymers, Vol. 1, H. Mark and 
R. Whitby, Ed., Wiley Interscience, New York, 1940.

5. H. A. Pohl, J. Am. Chem. Soc., 73, 5660 (1951).

6. P. D. Ritchie, in Soc. Chem. Ind. Monographs No. 13, London, 1961, p 107.

7. E. Ponnusamy, T. Balakrishnan, and $\mathrm{H}$. Kothandaraman, Makromol. Chem., 184, 1279 (1983).

8. C. T. Vijayakumar, E. Ponnusamy, T. Balakrishnan, and H. Kothandaraman, J. Polym. Sci., Polym. Chem. Ed., 20, 2715 (1982).

9. R. P. Sheldon, Polymer, 3, 213 (1962).

10. R. W. Lenz and A. N. Schuler, J. Polym. Sci., Polym. Symp., Ed., 63, 343 (1978).

11. E. Ponnusamy, C. T. Vijayakumar, T. Balakrishnan, and H. Kothandaraman, Polymer, 23, 1391 (1982).

12. G. Challa, Makromol. Chem., 38, 123 (1960)

13. A. W. Coats and J. P. Redfern, Nature, 201, 68 (1964).

14. C. D. Doyle, J. Appl. Polym. Sci., 6, 639 (1962).

15. P. Murray and J. White, Trans. Br. Ceram. Soc., 54, 151 (1955).

16. O. B. Edgar and E. Ellery, J. Chem. Soc., 2633 (1952).

17. S. Sonnerskog, Acta Chem. Scand., 10, 113 (1956).

18. E. F. Izard, J. Polym. Sci., 8, 503 (1952).

19. P. J. Flory, Trans. Faraday Soc., 51, 848 (1955).

20. L. Mandelkern, "Crystallization of Polymers," McGraw-Hill, Inc., New York, 1964, p 90. 